\title{
Influence of the Height of Light Shelves on Daylighting Classrooms: A Case of Two Windows in Two Different Orientations
}

\author{
Priyanka Baten* and Md. Ashikur Rahman Joarder \\ Department of Architecture, Bangladesh University of Engineering and Technology (BUET), Dhaka, Bangladesh
}

\begin{abstract}
Daylight is considered as one of the major aspects of sustainable architecture. Wellintegrated shading devices have the potential to increase daylighting quality inside classrooms and reduce energy consumption due to limited use of artificial lighting. This paper aims to study the impact of light shelves, at different heights on the illuminance and daylight efficiency in a classroom with two windows in two different orientations. A school building located in Dhaka is taken as a case building for the study. Daylight simulation is used to carry out the analysis by creating a virtual urban environment as found during physical survey. For creating the model, ECOTECT is used with a quick static simulation. As daylight highly depends on climate, climate based daylight simulation is done using RADIANCE-based DAYSIM simulation program. Light shelves at five different heights $(1500 \mathrm{~mm}, 1800 \mathrm{~mm}, 2100 \mathrm{~mm}, 2300 \mathrm{~mm}$ and $2400 \mathrm{~mm})$ are considered for a classroom of $3000 \mathrm{~mm}$ floor to ceiling height with two windows at south and east orientations. Six alternative models are created to carry out the daylight simulation study. Two types of metrics are used for the daylight simulation: static and dynamic metrics. The result showed that, for a classroom with two windows light shelves at a common height of $2100 \mathrm{~mm}$ from floor level performed better compared to other studied light shelves at alternate heights. The installation of light shelves at this optimal height help to reduce glare and ensure uniform distribution of day-light in classrooms.
\end{abstract}

Keywords: Daylight Simulation; Light-Shelves; Illuminance; Classroom

\section{Introduction}

Daylighting helps to create a comfortable indoor environment and enhances the opportunity to save energy in buildings. Daylighting inside a classroom improves the cognitive and social skills, helps in the process of learning, as well as improves psychological health (Yacan, 2014). In a study it is proved that, students in full spectrum daylit condition had fewer days of absence in a year compared to other students (Mirrahimi, Ibrahim and Surat, 2013). Having a full control over daylight is possible through implementation of an optimum shading device that will ensure passive solar heating in winter and reducing solar gain in summer (Shahdan, Ahmad and Hussin, 2018; Freewan, 2011). Research have proven that the integration of solar shading devices into buildings has many significant advantages in terms of reducing energy consumption and improving daylight quality. Lack of effective shading device allows excessive light to penetrate causing glare, hampers visual and thermal comfort of a space, as well as leads to non-uniform distribution of daylight in deep plan classrooms (Kontadakis, Tsangrassoulis, Doulos and Zerefos, 2017). A good daylighting condition can be achieved by ensuring appropriate illumination and distribution over work plane, having control over glare, appropriate contrast and color (Miran and Abdullah, 2016).

Light shelf is one of the passive architecture elements that provides shading as well as reflects light (Zakhour, 2015). The climatic condition of Dhaka is composite, where overcast as well as clear sky conditions are observed within a period of year. As a result, it becomes challenging to choose the design condition (Ahmed, 1987).In this study daylight simulation is performed for the custom light shelves for a classroom in a school building in the context of Dhaka with different sky conditions. This paper consists of major three parts. The first part describes the basic concept of light shelf and research methodology. The second part presents simulation 
analysis with static and dynamic metrics. Finally, comparisons of the findings are done to suggest the best possible height for light shelves for classrooms.

\section{Light Shelves}

Light shelf is one of the effective forms of shading device. It is a horizontal element that is positioned above eye level and divides the window into lower and upper parts. The lower part is the view area, which allows direct penetration of daylight. The upper part is known as the clerestory window that allows uniform distribution of daylight throughout the space (Joarder, Ahmad, Price and Mourshed, 2019). Light shelf also acts as a reflector that directs light to the deeper parts of a room (Zakhour, 2015).Therefore, light shelves with reflected surfaces, provide shading near the window, and brighten up part of ceiling towards the window, while redirect light to deeper parts (Ali and Ahmed, 2015). As a result, a continuous balanced luminous environment persists with less glare and contrast.

According to, Kontadakis, Tsangrassoulis, Doulos and Zerefos (2017), the parameters that affect light shelf performance are as following.

1. Geometry of the light shelf (e.g. width, length, installation height, tilt angle and shape).

2. Type of reflectance (e.g. diffuse or specular).

3. Type of material (e.g. perforated metal or translucent).

4. Position adjustment (e.g. rotation and operation).

5. Data of case study space (e.g. dimensions of room including ceiling shape).

6. Climatic and contextual conditions (e.g. sky condition, location and orientation).

The typical orientation of light shelves is the south in the northern hemisphere and north in the southern hemisphere. This study uses two light shelves made of metal deck with reflectance of 0.88 , installed in two different orientations (south and east). Adjusting the angle of light shelf can add some control over penetrated daylight, while it is widely believed that daylight does not increase especially under overcast sky conditions (Moazzeni and Ghiabaklou, 2016). Studies have shown that windows with internal light shelves produce an overall reduced daylight factor on the work plane, in contrast to openings without any light shelf (Littlefair, 1996). Among the wide spectrum of parameters, this study focuses on the height of the light shelf measured from the floor level and other parameters (such as length, color and material) are beyond the scope of the study.

\section{Methodology}

The quality and quantity of daylight inside a space is affected due to various factors. These parameters are architectural feature of the space, geometry of the openings; parameters related to site such as microclimate, latitude and finally time independent parameters e.g. solar azimuth angle and altitude (Moazzeni and Ghiabaklou, 2016).The climatic characteristics of Dhaka are different from other cities due to the location and rapid development in infrastructure. The case building selection ensured that it is located in the urban fabric of Dhaka (Figure 1) and used for educational purposes. In addition to that, the building façade should have suitable facades for installation of light shelf and the internal layout should have potential to allow ample penetration and distribution of daylight. 


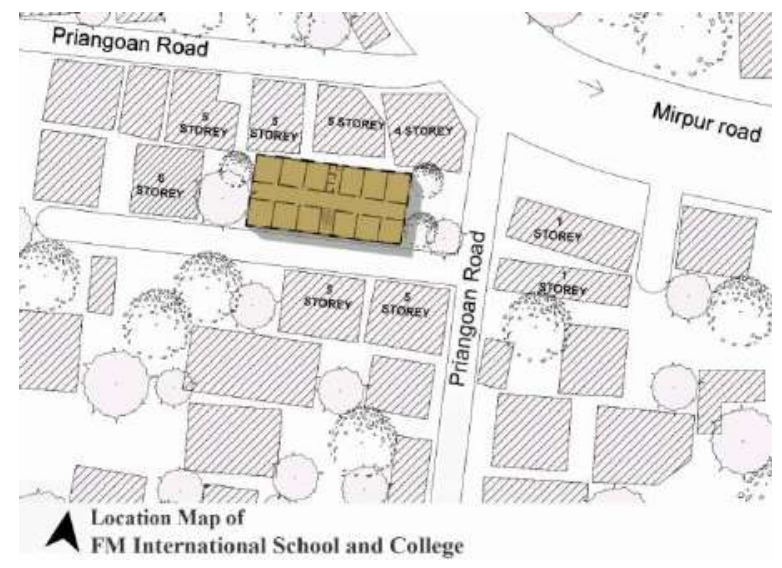

Figure 1: Site and surrounding of case building

The selection of case building for the simulation is carried out by critical case sampling technique. Critical sampling involves selection of selected number of samples suitable for study and then evaluated (Etikan, Musa and Alkassim, 2016). After the survey of ten school buildings, the case building is selected based on the criteria as mentioned. It is a six story school building named, FM International School and College (Figure 2). The building has $4500 \mathrm{~mm}$ feet wide roads on the east and south sides, while north and west sides are surrounded by six story apartment buildings.

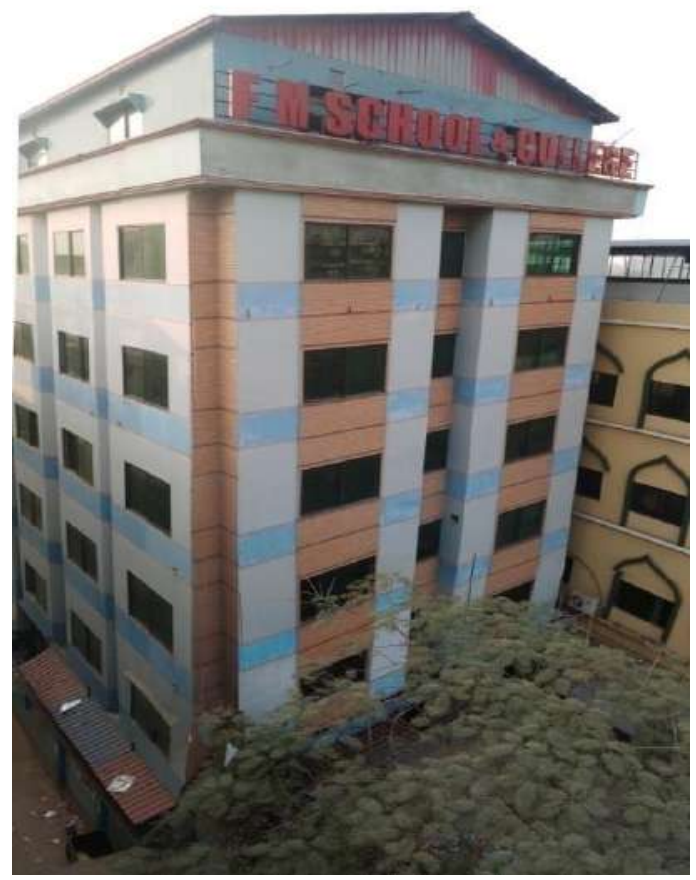

Figure 2: Image of six story case building

The building has typical floor plans, except the ground floor which is used for administrative purposes. The study intends to find out the impact of the height of light shelves on the illuminance inside a classroom where daylight enters from two directions, so a typical classroom on the south-east corners is selected for the simulation (Figure 3) which has a typical furniture layout and dimensions. The architectural features of the selected classroom as found during the physical survey are as following. 
1. Dimension: $(3900 \mathrm{X} 4600) \mathrm{mm}$

2. Clear height: $3000 \mathrm{~mm}$

3. Window to floor ratio: 0.15

4. Work plane height: $750 \mathrm{~mm}$

5. Orientation of classroom: south-east

6. Direction of windows: east and south

7. Sunshade: no sunshade

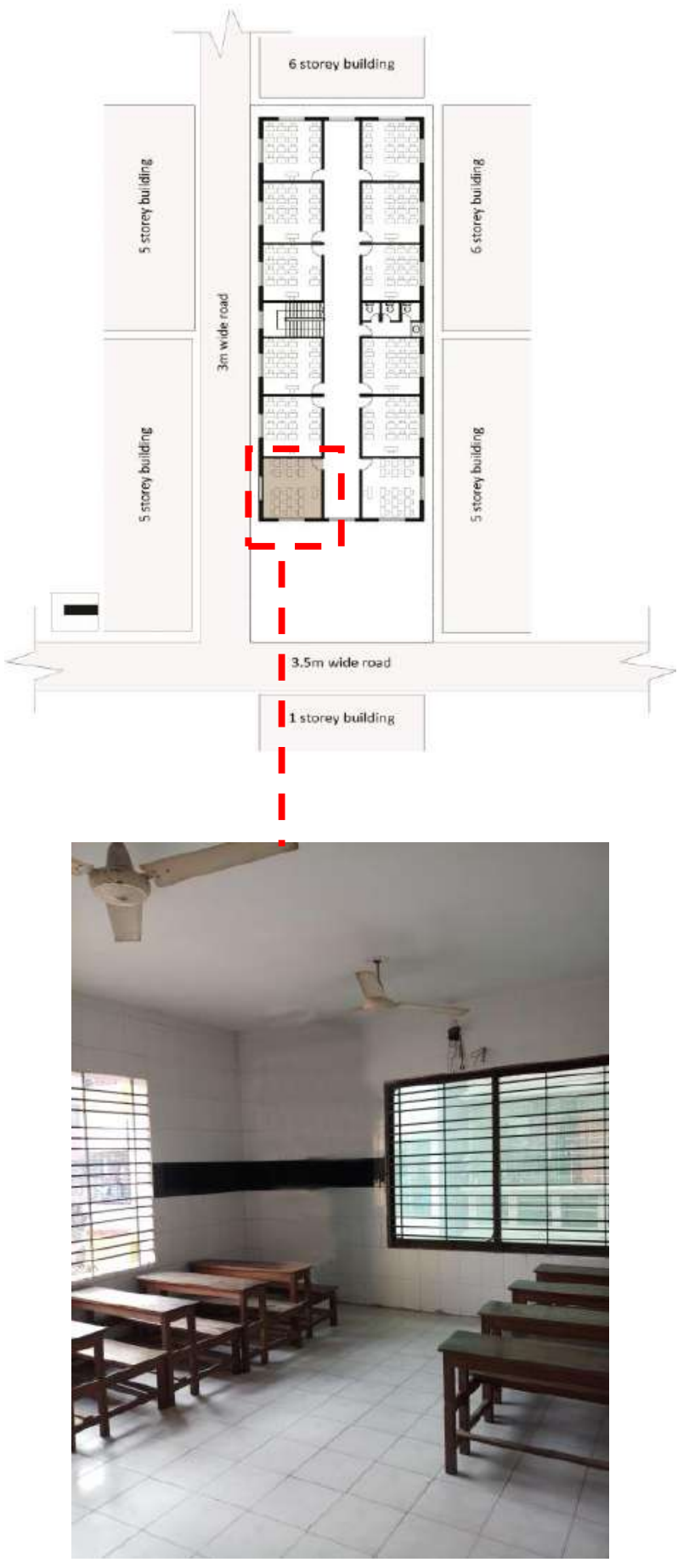

Figure 3: Location and image of the studied room 


\section{Simulation Study}

Daylight simulation could be used in architecture designing process and evaluation of existing buildings. The quantity and quality of daylight penetration inside a classroom due to variation of light shelves heights can be assessed by daylight simulation. It often becomes difficult to isolate the effect of one single factor in reality. Simulation enables to study the effect of a particular aspect, while keeping other factors constant. Simulation allows studying the lighting quality inside a space for any particular time of the year by assigning certain parameters, such as location, time, date and others (Joarder, Ahmed, Price and Mourshed, 2009).

Two types of performance metrics are followed in this study during daylight simulation: static and dynamic. The static performance metrics follow the Daylight Factor (DF) approach, which is based on a single sky model (overcast sky). DF approach is irresponsive of the orientation of the building. On the other hand, dynamic performance metrics follow the Daylight Coefficient (DC) approach. DC considers the surroundings and the changing climate characteristics of building location separately (Nabil and Mardaljevic, 2006).

In order to analyze the impact of light shelves at different heights on the daylight level on the desk plane, this study uses three simulation software. The 3D modeling is done using the highly comprehensive building analysis software ECOTECT V5.20; it has the function to analyze the lighting, thermal, shading, energy and acoustic performance (Joarder and Price, 2012). Secondly, a more accurate daylight simulation tool Desktop RADIANCE 2.0 Beta is used for comparison of visual images for luminance level. Finally, dynamic-climate based daylight simulation program DAYSIM is used to compare the impacts of design variants on indoor lighting situation, on annual basis (Reinhart, Mardaljevic and Rogers, 2013).

\section{Simulation Parameters}

During daylight simulation the indoor and outdoor conditions are kept same as found during physical survey. The interior space of the model is considered vacant during the simulation, without furniture, to avoid any kind of hindrance from these objects. The model is created considering unshaded peripheral glazing envelope. To make the simulation process faster, other floors of the building are kept hidden, as they do not have any contribution to the lighting analysis. Other parameters such as material finish and geometric dimension of the space are kept same (Joarder, Ahmed, Price and Mourshed, 2009) as found during the field survey. The Daylight simulation followed the following parameters.

- Location: Dhaka, Bangladesh $\left(90.2^{0} \mathrm{E} ; 23.5^{0} \mathrm{~N}\right)$

- Time: $17^{\text {th }}$ March, $1.30 \mathrm{pm}$ ( Time of physical measurements of daylight)

- Calculation Setting: Full daylight analysis

- Precision: High

- Local Terrain: Urban

- Window (Glass on Dirt): Average

- Sky Illumination Model: CIE Overcast

- Design Sky Illuminance: 16,500Lux (Khan,2005)

Physical survey of the selected classroom was carried out to find out architectural features. The following parameters of material finish and window are used during the simulation study.

- Ceiling/Roof of Classrooms: White painted plaster (reflectance: 0.5).

- Internal wall: Ceramic tile finishes (reflectance:0.6)

- Floor: Ceramic tile finish (reflectance 0.6)

- Glazing: $3 \mathrm{~mm}$ single glass unit with aluminum frame (transmittance: 0.8 ) 


\section{Simulation evaluation process}

According to the LEED v4requirements and methods, for spaces greater than 14 square meters, measurements of maximum $3000 \mathrm{~mm}$ square grid is recommended. The study classroom 17.94 square meters $(3900 \mathrm{~mm} \mathrm{X}$ $4600 \mathrm{~mm}$ ) is divided equally into $450 \mathrm{~mm}$ X 450mm grids as shown in Figure 4. Total 72 intersecting grid points are selected to generate daylight levels on ECOTECT and located at 750mm above the floor finish, which represent the desk height of classrooms (Joarder, 2007).

In order to set a comparison basis, additional axes XX' and YY' are created through the center of the case space and middle of the two windows to observe the change of luminance away from the windows and into deeper parts of the classroom. The furniture layout of the classroom is such that the sensor points on XX' and YY' axes are mostly on desk top levels. The sensor points on XX' and YY' axes are considered as the core sensor points as shown in Table 1.

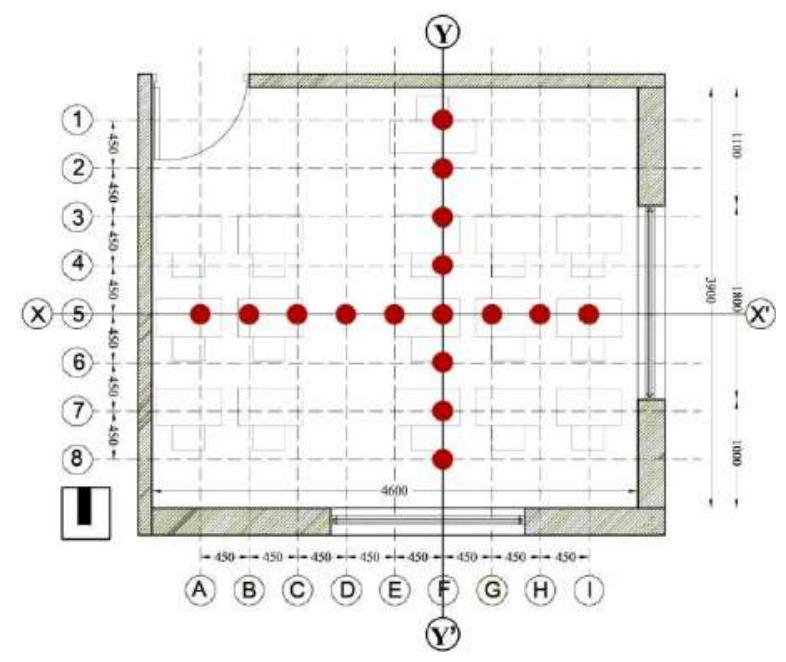

Figure 4: Plan showing all the grid points and analysis axes lines on the study space

Table 1: Codes and core sensor points

\begin{tabular}{lllllllll}
\hline & $\mathbf{1}$ & $\mathbf{2}$ & $\mathbf{3}$ & $\mathbf{4}$ & $\mathbf{5}$ & $\mathbf{6}$ & $\mathbf{7}$ & $\mathbf{8}$ \\
\hline $\mathbf{A}$ & $1 \mathrm{~A}$ & $2 \mathrm{~A}$ & $3 \mathrm{~A}$ & $4 \mathrm{~A}$ & $\mathbf{5 A}$ & $6 \mathrm{~A}$ & $7 \mathrm{~A}$ & $8 \mathrm{~A}$ \\
\hline $\mathbf{B}$ & $1 \mathrm{~B}$ & $2 \mathrm{~B}$ & $3 \mathrm{~B}$ & $4 \mathrm{~B}$ & $\mathbf{5 B}$ & $6 \mathrm{~B}$ & $7 \mathrm{~B}$ & $8 \mathrm{~B}$ \\
\hline $\mathbf{C}$ & $1 \mathrm{C}$ & $2 \mathrm{C}$ & $3 \mathrm{C}$ & $4 \mathrm{C}$ & $\mathbf{5 C}$ & $6 \mathrm{C}$ & $7 \mathrm{C}$ & $8 \mathrm{C}$ \\
\hline $\mathbf{D}$ & $1 \mathrm{D}$ & $2 \mathrm{D}$ & $3 \mathrm{D}$ & $4 \mathrm{D}$ & $\mathbf{5 D}$ & $6 \mathrm{D}$ & $7 \mathrm{D}$ & $8 \mathrm{D}$ \\
\hline $\mathbf{E}$ & $1 \mathrm{E}$ & $2 \mathrm{E}$ & $3 \mathrm{E}$ & $4 \mathrm{E}$ & $\mathbf{5 E}$ & $6 \mathrm{E}$ & $7 \mathrm{E}$ & $8 \mathrm{E}$ \\
\hline $\mathbf{F}$ & $\mathbf{1 F}$ & $\mathbf{2 F}$ & $\mathbf{3 F}$ & $\mathbf{4 F}$ & $\mathbf{5 F}$ & $\mathbf{6 F}$ & $\mathbf{7 F}$ & $\mathbf{8 F}$ \\
\hline $\mathbf{G}$ & $1 \mathrm{G}$ & $2 \mathrm{G}$ & $3 \mathrm{G}$ & $4 \mathrm{G}$ & $\mathbf{5 F}$ & $6 \mathrm{~F}$ & $7 \mathrm{~F}$ & $8 \mathrm{~F}$ \\
\hline $\mathbf{H}$ & $1 \mathrm{H}$ & $2 \mathrm{H}$ & $3 \mathrm{H}$ & $4 \mathrm{H}$ & $\mathbf{5 H}$ & $6 \mathrm{H}$ & $7 \mathrm{H}$ & $8 \mathrm{H}$ \\
\hline $\mathbf{I}$ & $1 \mathrm{I}$ & $2 \mathrm{I}$ & $3 \mathrm{I}$ & $4 \mathrm{I}$ & $\mathbf{5 I}$ & $6 \mathrm{I}$ & $7 \mathrm{I}$ & $8 \mathrm{I}$ \\
\hline
\end{tabular}

The ECOTECT model is used to find out the daylight levels at each grid point on the desk plane with overcast sky. The ECOTECT models are then exported to the RADIANCE to create realistic rendered images of lighting levels inside the classroom. Lastly, DAYSIM creates dynamic performance metrics for the illuminance throughout the year for the particular climate. Based on simulation outputs, light shelves are assessed by the following criteria. 
- Average luminance on the desk plane height

- Number of points within acceptable illuminance level (300-900 lux)

- Comparison of rendered images for the luminance level of the space

- Evaluation with different annual performance metrics such as Daylight Autonomy (DA), Maximum Daylight Autonomy (DA $A_{\max }$ ) above 5\% and Useful Daylight Illumination (UDI).

\section{Simulation of Light Shelves}

In Dhaka city, maximum allowance of overhang width over mandatory open space is 0.234 times of the height of window (BNBC, 2015). The case building has window height of $1800 \mathrm{~mm}$, so the recommended width of shading device would be $430 \mathrm{~mm}$. The daylight simulation study uses custom light shelves at various heights.

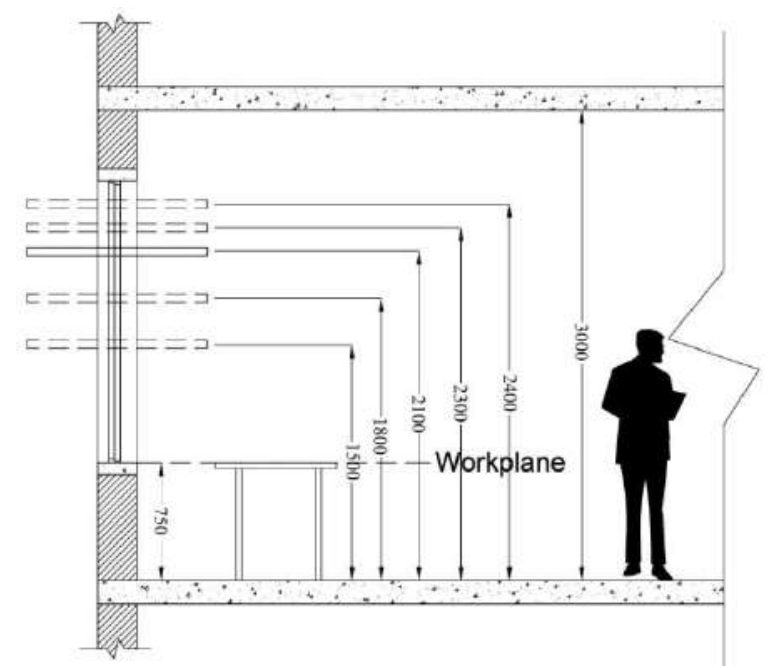

Figure 5: Section showing light shelves at different heights

Six different models are created with light shelves extending $430 \mathrm{~mm}$ on both sides at five different heights as shown in the Figure 5. The heights of installation for fixed light shelves are $1500 \mathrm{~mm}, 1800 \mathrm{~mm}, 2100 \mathrm{~mm}$, $2300 \mathrm{~mm}$ and $2400 \mathrm{~mm}$ from the floor level as shown in Table 2.

Table 2: Light shelf heights and types

\begin{tabular}{ll}
\hline Height of light shelf & Types \\
\hline None & Type 0 \\
\hline $1500 \mathrm{~mm}$ & Type A \\
\hline $1800 \mathrm{~mm}$ & Type B \\
\hline $2100 \mathrm{~mm}$ & Type C \\
\hline $2300 \mathrm{~mm}$ & Type D \\
\hline $2400 \mathrm{~mm}$ & Type E \\
\hline
\end{tabular}

\section{Static simulation results}

The results from the static simulations for 72 sensor points are presented graphically and evaluated. The illuminance value at analysis grid points are divided into three groups (Table 3). The first group represents the 
number of points that have illuminance value less than the minimum recommended value for classrooms (Number of points < 300 lux). The second group defines the number of points which lies within the recommended range of illuminance (Number of points between 300-900 lux). Finally, the third group represents number of points which have excessive lighting level and can cause glare (Number of glare points >900). As the number of points with illuminance value increases near the window façades, the contrast between visual field increases, hence it increases the chance of visual discomfort and glare (Zakhour, 2015).

Comparison of average illumination among five light shelves and without any light shelf showed that the condition without any light shelf has the highest average illumination of 663 lux (Figure 6). There are higher numbers of points above 900 lux (14points) and lowest number of points (37 points) lies within the recommended range between 300-900 lux (Figure 7).

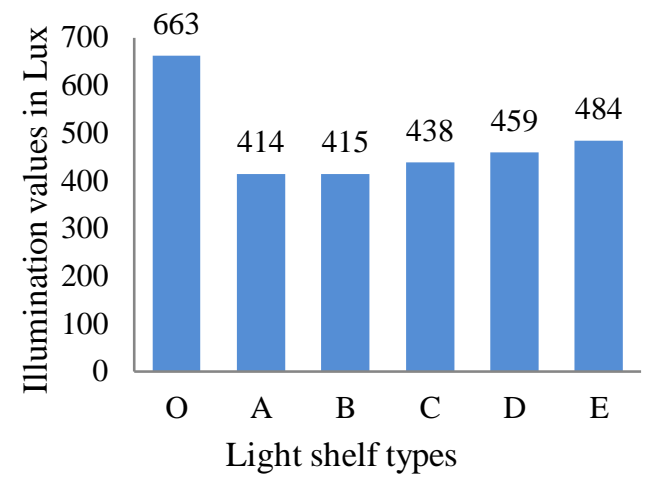

Average illumination

Figure 6: Average illumination level with no light shelf and light shelves at different heights

On the other hand, among the studied light shelves, the highest number of points among 300-900lux is for Type $\mathrm{D}$ (52points) and the lowest number of points exceeding 900lux range (5 points).Although the average illuminance value for Type D (459 lux) is less than Type E (484 lux), the number points above 900 lux are more (9points) and have lowest number of points among 300-900 lux range (40points) for Type E. In addition to that, Type D has only 15points below the range of 300lux. As a result, there is more risk of having discomfort glare and contrast in Type E.

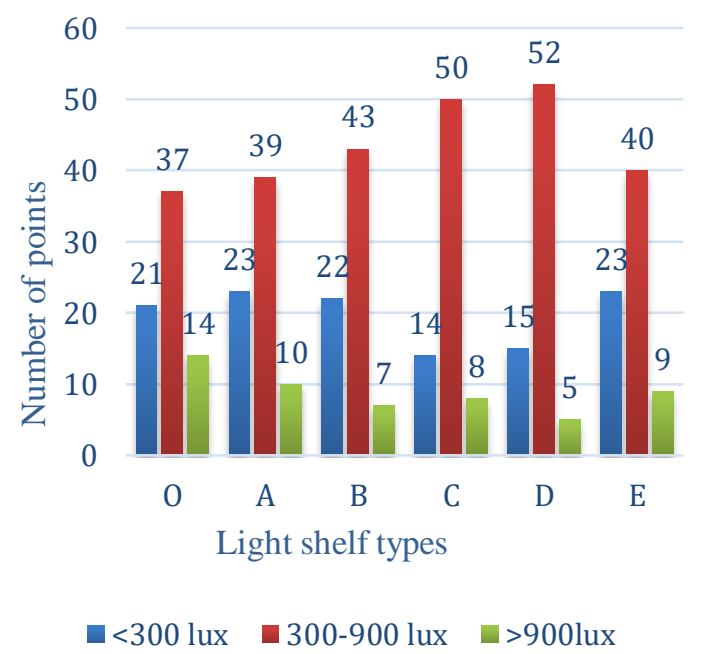

Figure 7: Number of points with illuminance level below 300lux, within 300-900 lux and above 900lux 
Baten \& Joarder / Influence of the Height of Light Shelves....

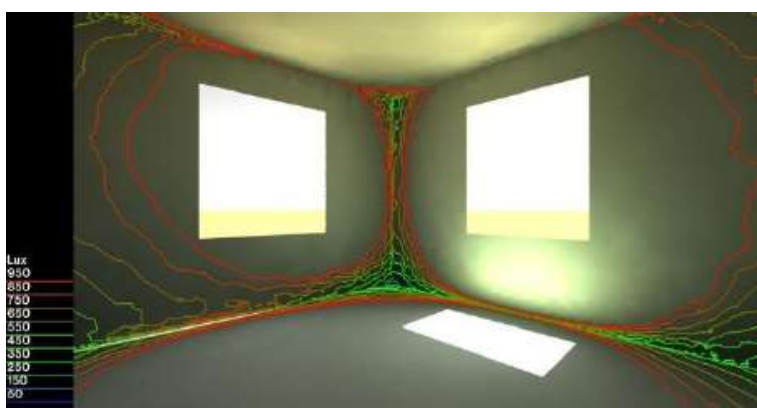

1. Type O-No Light shelf

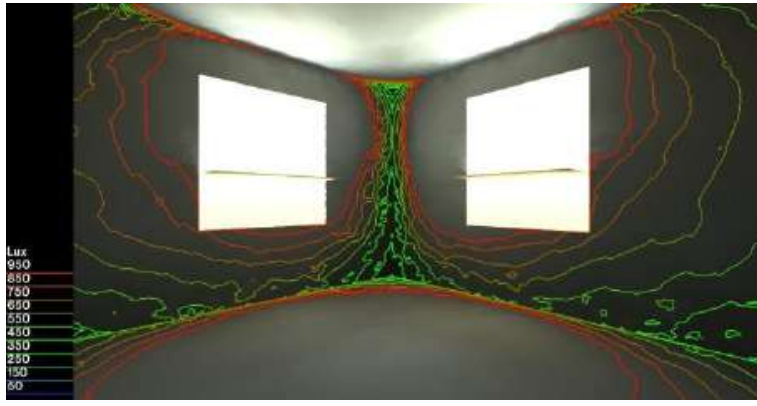

2. Type A-Light shelf at $1500 \mathrm{~mm}$ from floor level

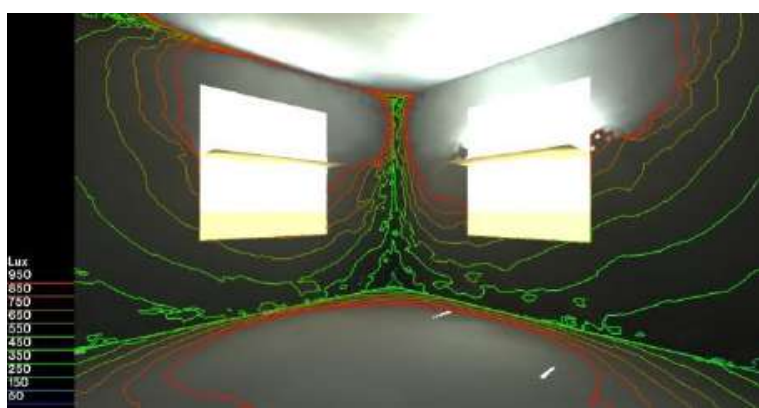

3. Type B-Light shelf at 1800mm from floor level

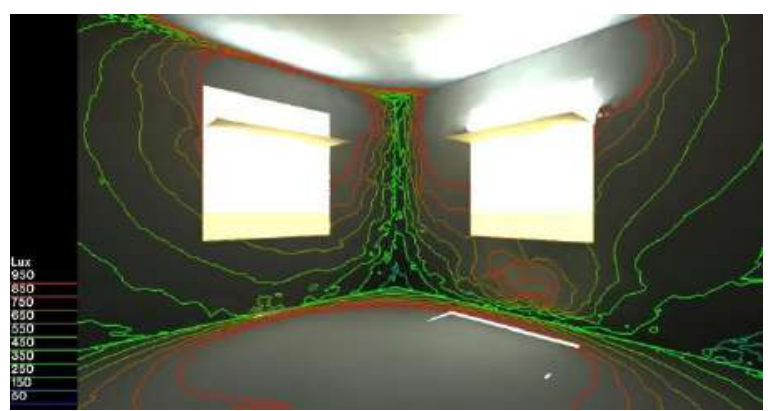

4. Type C-Light shelf at $2100 \mathrm{~mm}$ from floor level

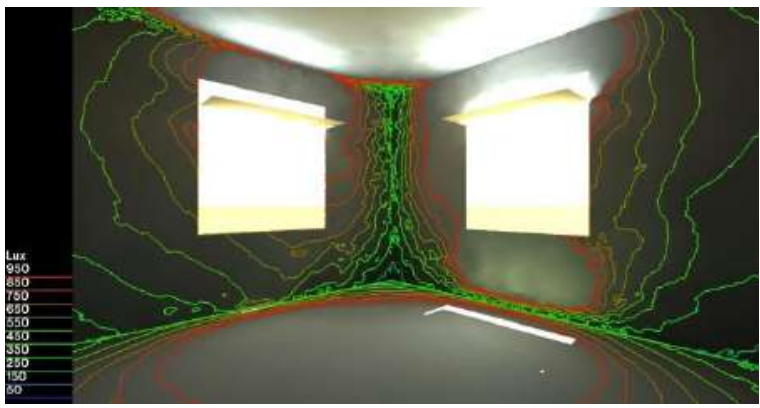

5. Type D-Light shelf at $2300 \mathrm{~mm}$ from floor level

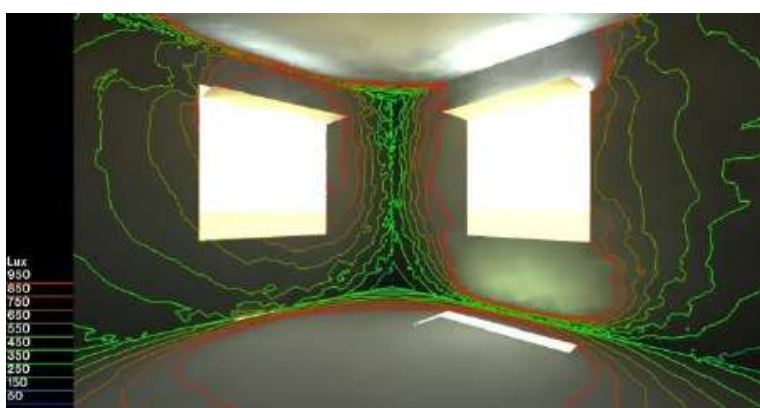

6. Type E-Light shelf at $2400 \mathrm{~mm}$ from floor level

Figure 8: Daylight contour distributions with light shelves at different heights and with no light shelf

The RADIANCE output in Figure 8 shows that the areas near the windows have higher luminance value and it gradually decreases towards the deepest parts. The space is brightest for light shelf at 2300mm (Type D) whereas, it is darkest for light shelf at $1500 \mathrm{~mm}$ (Type A).

The results from static simulation are ranked accordingly on the basis of their performance as shown in Table 3 . Rating points are given between 
1 to 6 points; highest point (6points) means best performance, whereas, lowest point (1 point) indicates worst performance among the studied options. The score of each performance metric are then summed up to get the final score. Finally, the raking is done; higher the score, higher is the rank. Table 3 shows that, light shelf at 2300mm (Type D) scored the highest point and ranked as first, followed by Type C, Type B, Type E, Type O and Type A respectively. Considering the static aspects, light shelf at 2300mm (Type D) seems feasible to improve daylighting quality inside a classroom. Figure 9 indicates the daylight distribution of node points with light shelf at $2300 \mathrm{~mm}$ shows that there is uniform distribution of daylight, hence reduces contrast towards the deeper parts of the classroom.

Table 3: Static simulation results and ranking for light shelf at various heights and with no light shelf

\begin{tabular}{|c|c|c|c|c|c|c|c|}
\hline 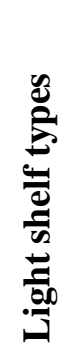 & 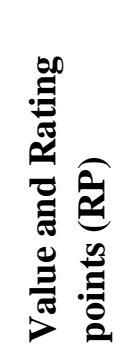 & 总 & 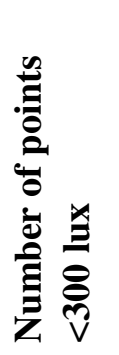 & 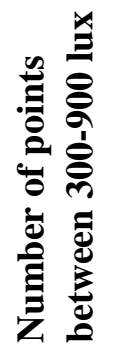 & 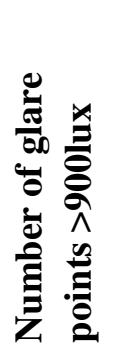 & 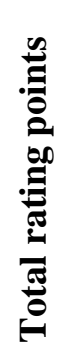 & 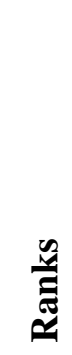 \\
\hline \multirow[t]{2}{*}{$\mathbf{O}$} & Value & 663 & 21 & 37 & 14 & \multirow{2}{*}{-12} & \multirow{2}{*}{5 th } \\
\hline & $\mathrm{RP}$ & 6 & 4 & 1 & 1 & & \\
\hline \multirow[t]{2}{*}{$\mathbf{A}$} & Value & 414 & 23 & 39 & 10 & \multirow{2}{*}{-7} & \multirow{2}{*}{ 6th } \\
\hline & $\mathrm{RP}$ & 1 & 2 & 2 & 2 & & \\
\hline \multirow[t]{2}{*}{ B } & Value & 415 & 22 & 43 & 7 & \multirow{2}{*}{14} & \multirow{2}{*}{$3 r d$} \\
\hline & $\mathrm{RP}$ & 2 & 3 & 4 & 5 & & \\
\hline \multirow[t]{2}{*}{$\mathbf{C}$} & Value & 438 & 14 & 50 & 8 & \multirow{2}{*}{18} & \multirow{2}{*}{ 2nd } \\
\hline & $\mathrm{RP}$ & 3 & 6 & 5 & 4 & & \\
\hline \multirow[t]{2}{*}{ D } & Value & 459 & 15 & 52 & 5 & \multirow{2}{*}{21} & \multirow{2}{*}{ 1st } \\
\hline & $\mathrm{RP}$ & 4 & 5 & 6 & 6 & & \\
\hline \multirow[t]{2}{*}{$\mathbf{E}$} & Value & 484 & 23 & 40 & 9 & \multirow{2}{*}{13} & \multirow{2}{*}{ 4th } \\
\hline & $\mathrm{RP}$ & 5 & 2 & 3 & 3 & & \\
\hline
\end{tabular}




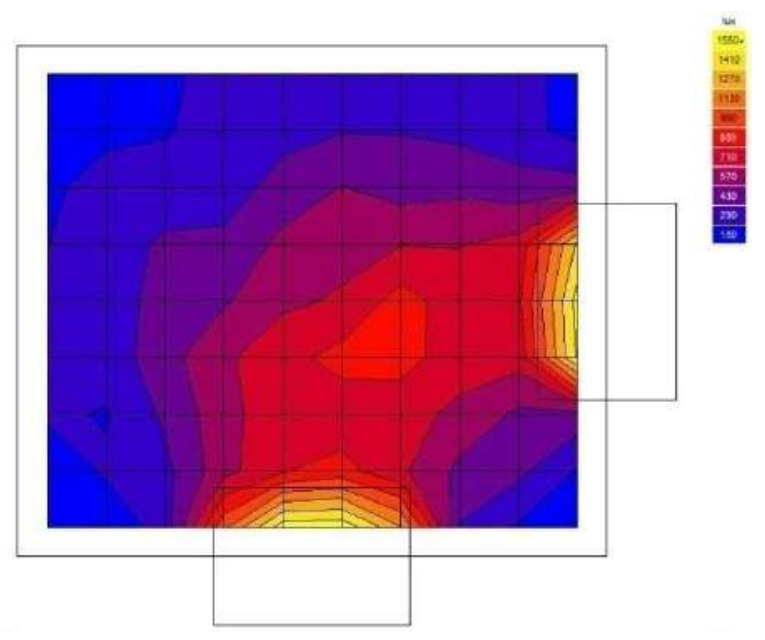

Figure 9: Daylight distributions on node points with light shelf at 2300mm (Type D)

\section{Dynamic simulation results}

Dynamic simulation considers different types of sky conditions and the analysis is done on annual basis. To ensure more accuracy, simulation process is carried out by using DAYSIM. The goal of the dynamic simulation analysis is to provide minimum 300lux at each sensor point at desk plane height. The 7 hours duration was taken between 8:00am to 3:00pm, which is the school hours for the case school. The performances of the light shelves are compared with respect to various dynamic metrics: DA, DA $A_{\max }$ and UDI. The results of simulation are then evaluated and ranked accordingly based on their value point (Table 4).

DA is defined as the percentage of occupied time when minimum illuminance is met by daylight alone (Reinhart, Mardaljevic and Rogers, 2013). It is shown in Table 4 that, Type O scored highest point with the highest DA value (99.6\%), while, Type D scored lowest point with 99.3\% DA value.

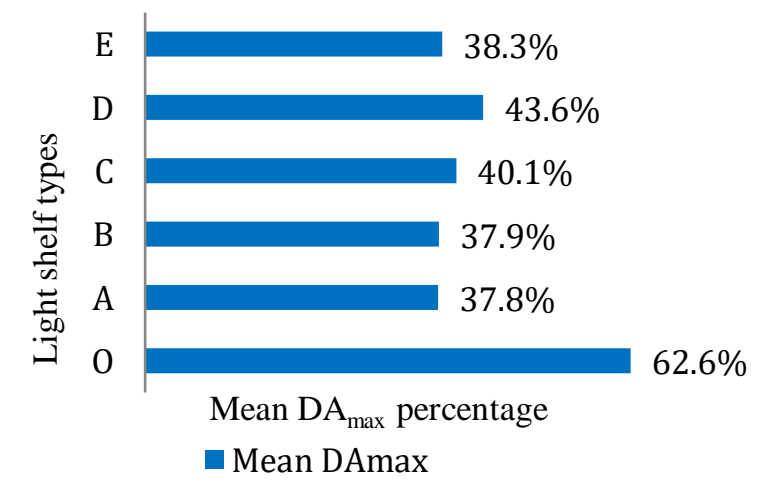

Figure 10: Mean DAmax metric performance analysis for different types of light shelves

$\mathrm{DA}_{\max }$ refers to the time when the daylight is ten times greater than the design illumination (Reinhart, Mardaljevic and Rogers, 2013). Figure 10 shows that Type A performs better with lowest mean value (37.8\%) whereas; Type 0 has the highest value (62.6\%) which indicates poor performance.

UDI indicates when the daylight level is useful for the user and when it is not. UDI results in three metrics; UDI $100-2000$ is the percentage of occupied times when the daylight is useful, whereas, $\mathrm{UDI}_{<100}$ indicates that the space is too dark and UDI $>_{2000}$ means it is too bright or indication of glare (Nabil and Mardaljevic, 2006). Table 4 shows the UDI value on the core sensor points for the studied light shelves and without any light shelf. On an 
average, Type $\mathrm{C}$ has scored highest point (75.3\%), whereas Type 0 scored lowest value point (69.8\%) in $\mathrm{UDI}_{100-}$ 2000. This indicates that for most of the occupied time of the year, the light levels will be in recommended range for light shelf at height $2100 \mathrm{~mm}$ from floor. In terms of $\mathrm{UDI}_{<100}$, the value for Type D is the lowest $(7.1 \%)$ and scored highest rating points, while Type O scored lowest point with $10.9 \%$ value. The result for UDI $<100$ shows that, the space will have less illumination below the recommended range for Type D light shelf. On the other hand, Type B scored highest rating points for $\mathrm{UDI}_{>2000}(17.2 \%)$, which means there will be less glare throughout the year, while Type O scored lowest value with $19.3 \% \mathrm{UDI}_{>2000}$ value.

Table 4: Dynamic simulation results for light shelves at five alternative heights and without any light shelf

\begin{tabular}{|c|c|c|c|c|c|c|c|c|}
\hline 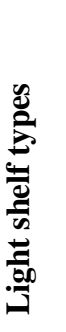 & 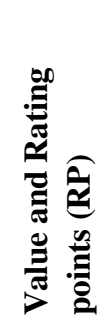 & $\frac{\sqrt{2}}{\sqrt{2}}$ & 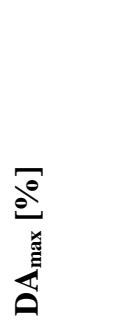 & $\begin{array}{l}\frac{2}{8} \\
\frac{8}{8} \\
\frac{1}{3} \\
\frac{5}{3}\end{array}$ & $\frac{\sqrt{2}}{\frac{8}{v}}$ & 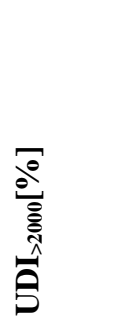 & 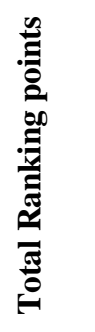 & 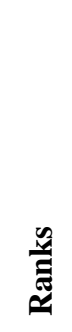 \\
\hline \multirow[t]{2}{*}{ O } & Value & 99.6 & 62.6 & 69.8 & 10.9 & 19.3 & \multirow{2}{*}{10} & \multirow{2}{*}{ 6th } \\
\hline & $\mathrm{RP}$ & 6 & 1 & 1 & 1 & 1 & & \\
\hline \multirow[t]{2}{*}{ A } & Value & 99.5 & 37.8 & 73.8 & 7.6 & 18.6 & \multirow{2}{*}{22} & \multirow{2}{*}{ 2nd } \\
\hline & $\mathrm{RP}$ & 5 & 6 & 4 & 4 & 3 & & \\
\hline \multirow[t]{2}{*}{ B } & Value & 99.5 & 37.9 & 73.2 & 9.6 & 17.2 & \multirow{2}{*}{21} & \multirow{2}{*}{ 3rd } \\
\hline & $\mathrm{RP}$ & 5 & 5 & 3 & 2 & 6 & & \\
\hline \multirow[t]{2}{*}{$\mathbf{C}$} & Value & 99.4 & 40.1 & 75.3 & 7.3 & 17.4 & \multirow{2}{*}{23} & \multirow{2}{*}{ 1st } \\
\hline & $\mathrm{RP}$ & 4 & 3 & 6 & 5 & 5 & & \\
\hline \multirow[t]{2}{*}{ D } & Value & 99.3 & 43.6 & 75.1 & 7.1 & 17.8 & \multirow{2}{*}{20} & \multirow{2}{*}{ 4th } \\
\hline & $\mathrm{RP}$ & 3 & 2 & 5 & 6 & 4 & & \\
\hline \multirow[t]{2}{*}{$\mathbf{E}$} & Value & 99.4 & 38.3 & 72.4 & 8.9 & 18.7 & \multirow{2}{*}{15} & \multirow{2}{*}{5 th } \\
\hline & $\mathrm{RP}$ & 4 & 4 & 2 & 3 & 2 & & \\
\hline
\end{tabular}

Table 4 shows that, Type $\mathrm{C}$ is ranked top with highest rating points, followed by Type A, Type B, Type D, Type $\mathrm{E}$ and finally Type O. Evaluation of the dynamic performance metrics for the light shelves indicates that, light shelf at height $2100 \mathrm{~mm}$ performs better compared to light shelves at other studied heights. 


\begin{tabular}{lcccccc}
\hline \multirow{2}{*}{$\begin{array}{l}\text { Static simulation } \\
\text { Dynamic } \\
\text { simulation }\end{array}$} & 5 th & 6th & 3rd & 2nd & 1st & 4 th \\
\hline
\end{tabular}

The result from static simulation indicates that light shelf at height 2300mm (Type D) performs better than light shelves at other heights from finished floor level. Dynamic simulation shows that, light shelf at height $2100 \mathrm{~mm}$ (Type C) is the most feasible among others as shown in the Table 5. Static simulation follows DF approach (the more the better), while, Dynamic simulation follows DC approach (Nabil and Mardaljevic, 2006). DF approach is limited to overcast sky condition and does not consider practical daylighting conditions precisely. DF is not context specific, i.e. it does not consider site and surrounding. On the other hand, DC approach considers all type of sky condition in the context on annual basis. The characteristics of the building and site are considered separately along with direction of sun in DC. Dynamic simulation gives more sensible results by indicating glare and other measures (Reinhart, Mardaljevic and Rogers, 2013). As a summary, light shelf at height $2100 \mathrm{~mm}$ (Type C) from the floor is recommended as the most feasible light shelf among the studied light shelves in this research.

\section{Conclusion}

Daylight in educational buildings helps to decrease stress level, improves health condition and as a result increases the efficiency of students as well as success rate increases (Subramanian and Kamalesvari, 2016). This simulation study is carried out to determine the best possible height for light shelves installed at a classroom with windows in two facades (south and east) in a school building in Dhaka. The result of this study agreed with the previous studies that introduction of light shelf at any height results in overall reduction of illumination on the desk plane height throughout the study space. The findings showed that, light shelves at height $2100 \mathrm{~mm}$ in a $3000 \mathrm{~mm}$ clear height classroom perform better to improve the daylighting quality of the interior space than other studied heights. During simulation study other design parameters such as material, angle, surface property, shape are kept constant, which might have significant influence on the daylighting quality inside an interior space. Further studies could be done to investigate and compare other mentioned parameters with the same setting. Finally, light shelf can enhance the quality inside an educational space, if it is designed and installed properly.

\section{Acknowledgement}

We would like to show our gratitude to all the people who helped us at every stage of the investigation. Most importantly thanks to Mohammad Firoz Mukul, the founder of FM International School and college for cooperation. Thanks to the department of Architecture, Bangladesh University of Engineering and Technology, for the technical support. 


\section{References}

ALI, A.A. and AHMED, T.M., 2012, Evaluating the impact of shading devices on the indoor thermal comfort of residential buildings in Egypt. Proceedings of SimBuild, 5(1),603-612.

AHMED, K.S., 1995,Approaches to bioclimatic urban design for the tropics with special reference to Dhaka, Bangladesh. Doctoral dissertation, Open University.

BANGLADESH NATIONAL BUILDING CODE (BNBC), 2015 (Draft). Housing and Building Research Institute and Bangladesh Standards and Testing Institute, City Art press Ltd, Dhaka.

BANGLADESH NATIONAL BUILDING CODE (BNBC), 2012 (Draft). The govt. of the people's republic of Bangladesh, Ministry of Housing and Public Works, Part 8, Chapter 01.

BERARDI, U. and ANARAKI, H.K., 2018, The benefits of light shelves over the daylight illuminance in office buildings in Toronto. Indoor and Built Environment, 27(2),244-262.

ETIKAN, I., MUSA, S.A. and ALKASSIM, R.S., 2016, Comparison of convenience sampling and purposive sampling. American journal of theoretical and applied statistics, 5(1),1-4.

FREEWAN, A.A., 2011, November. Improving thermal performance of offices in JUST using fixed shading devices. In World Renewable Energy Congress-Sweden; 8-13 May; 2011; Linköping; Sweden,No. 057, pp. 1860-1866.

JOARDER, A.R. and PRICE, A.D., 2013, Impact of daylight illumination on reducing patient length of stay in hospital after coronary artery bypass graft surgery. Lighting Research \& Technology, 45(4),435-449.

JOARDER, M.A.R., 2007, A Study of Daylight Inclusion in Luminous Environment of Offices in Dhaka City, M. Arch Thesis (unpublished), Department of Architecture, BUET, Dhaka.

JOARDER, M., RAHMAN, A., AHMED, Z.N., PRICE, A. and MOURSHED, M., 2009, A simulation assessment of the height of light shelves to enhance daylighting quality in tropical office buildings under overcast sky conditions in Dhaka, Bangladesh, Accessed: 05-07-2018. Available at: http://www.ibpsa.org/proceedings/BS2009/BS09_1706_1713.pdf

KONTADAKIS, A., TSANGRASSOULIS, A., DOULOS, L. and ZEREFOS, S., 2017, A Review of Light Shelf Designs for Daylit Environments. Sustainability, 10(1), 1-24.

LITTLEFAIR, P.J., 1996, Designing with innovative daylighting. Building Research Establishment Report. Construction research Communications.

MOAZZENI, M.H. and GHIABAKLOU, Z., 2016, Investigating the influence of light shelf geometry parameters on daylight performance and visual comfort, a case study of educational space in Tehran, Iran. Buildings, 6(3), 26.

MIRRAHIMI, S., NIK IBRAHIM, N. and SURAT, M. 2018, Effect of daylighting on student health and performance. [Online] Malaysia: Department of Architecture Faculty of Engineering and Built Environment National University of Malaysia, pp.127-132, Accessed: 18 Feb. 2018.Available at: http://www.wseas.us/elibrary/conferences/2013/Malaysia/MACMESE/MACMESE-20.pdf.

MIRAN, F.D. and ABDULLAH, H.K., 2016, Evaluation of the Optimal Solar Shading Devices for Enhancing Daylight Performance of School Building. A case study of semi-arid climate-Erbil city. ZANCO J. Pure Appl. Sci, 28, 580-598.

NABIL, A. and MARDALJEVIC, J., 2006, Useful daylight illuminance: A replacement for daylight factors. Energy and buildings, 38(7),905-913.

REINHART, C.F., MARDALJEVIC, J. and ROGERS, Z., 2006, Dynamic daylight performance metrics for sustainable building design. Leukos, 3(1),7-31.

SHAHDAN, M.S., AHMAD, S.S. and HUSSIN, M.A., 2018, February. External shading devices for energy efficient building. In IOP Conference Series: Earth and Environmental Science,Vol. 117, No. 1, pp. 012034

SUBRAMANIAN, C.V. and KAMALESVARI, S., 2016, Daylight and Sustainable Architecture for Warm Humid climate. Mirror (glass),80, pp. 90. 
YACAN, S., 2014, Impacts of daylighting on preschool students' social and cognitive skills, Accessed: 17 Feb. 2019. Available at: https://digitalcommons.unl.edu/cgi/viewcontent.cgi?article=1010\&context=arch_id_theses .

ZAKHOUR, S., 2015, The Influence of Selected Design Parameters on the Performance of Light Shelves under Overcast Conditions. Architecture Research, 5(4), 113-120. 